\title{
Pengaruh Kedalaman Terhadap Kelangsungan Hidup (Survival Rate) Benih Tiram Mutiara (Pinctada maxima) Stadia Spat
}

\author{
Raismin Kota* \\ Pusat Penelitian Oseanografi LIPI \\ Email: rasimin_kota@gmail.com
}

\begin{abstract}
ABSTRAK
Tiram mutiara banyak ditemukan di perairan Indonesia salah satunya adalah tiram mutiara jenis Pinctada maxima. Jenis ini dikenal mampu menghasilkan mutiara yang berukuran cukup besar di kelasnya. Penelitian ini bertujuan melihat pengaruh kedalaman yang berbeda terhadap kelangsungan hidup (Survival Rate) benih tiram mutiara (Pinctada maxima) dan mengetahui kedalaman terbaik untuk kelangsungan hidup benih tiram mutiara stadia spat. Hasil pengamatan menunjukkan bahwa kelangsungan hidup benih tiram mutiara stadia spat tertinggi terjadi pada perlakuan K2 (kedalaman $6 \mathrm{~m}$ ) dengan kelangsungan hidup (SR) sebesar 96\% dikuti K1 (kedalaman 2 m) 92\%, dan terendah K4 (kedalaman $14 \mathrm{~m})$ sebesar 79\%. Berdasarkan hasil Analisa Sidik Ragam (ANASRA) menunjukkan bahwa kelangsungan hidup tiram mutiara stadia spat pada masingmasing perlakuan Tidak Berbeda Nyata (non signifikan) dimana F hitung $<F$ tabel $5 \%(3,80<4.07)$, Hal ini disebabkan juga karena kualitas perairan yang diukur berada pada kisaran toleransi yang disukai tiram mutiara. Hasil pengamatan kualitas air seperti suhu 26,8 oC-28,9oC, pH 7-8, salinitas 32-34 ppt serta kecepatan arus $20-27 \mathrm{~cm} /$ detik.
\end{abstract}

Kata Kunci : Kedalaman, Kelangsungan hidup tiram mutiara stadia spat

\section{PENDAHULUAN}

Mutiara memiliki manfaat selain untuk perhiasan, juga dapat digunakan sebagai bahan dasar kosmetik. Pembudidayaan mutiara dianggap sangat perlu karena meningkatnya permintaan pasar terhadap mutiara alami, yang mengakibatkan persediaan mutiara di alam semakin terbatas dan untuk mendapatkan jenis mutiara yang sesuai dengan selera pasar juga semakin sulit. Kondisi ini mendorong manusia menganggap perlu mengembangkan budidaya kerang mutiara untuk mendapatkan kualitas mutiara yang terbaik.

Jenis kerang mutiara yang banyak ditemukan di Indonesia antara lain kerang mutiara jenis Pinctada maxima (Gambar 1), dimana jenis ini dikenal mampu menghasilkan mutiara yang berukuran cukup besar di kelasnya. Lingkungan perairan tropis Indonesia sangat mendukung kehidupan kerang mutiara sehingga pertumbuhannya dapat berlangsung sepanjang tahun. Pertumbuhan kerang di daerah subtropis berlangsung pada musim panas (summer) sedangkan di musim dingin (winter) pertumbuhannya berlangsung lambat atau terkadang tidak mengalami pertumbuhan sama sekali. Hal inilah yang menyebabkan waktu pertumbuhan kerang mutiara di Indonesia (daerah tropis) cenderung 4,6 kali lebih cepat dibandingkan dengan kerang mutiara Jepang (daerah subtropis).

Kerang mutiara dapat hidup di perairan pada kisaran salinitas antara $24 \mathrm{ppt}$ dan $50 \mathrm{ppt}$, sedangkan kisaran ideal untuk peertumbuhan dan kelangsungan hidupnya adalah antara 3235 ppt (Dhoe, et al, 2001). Suhu yang baik untuk kelangsungan hidup kerang mutiara berkisar antara 25-30 oC, $\mathrm{pH}$ antara 7,8-8,6 dan oksigen terlarut antara 5,2-6,6 ppm (Ditjen Perikanan Budidaya, 2005).

Kegiatan budidaya tiram mutiara diawali dengan kultur pakan hidup, pembenihan, 
pemeliharaan larva, pemeliharaan spat, pendederan, pembesaran dan pemanenan. Salah satu tahapan penting dalam kegiatan budidaya tiram mutiara adalah kegiatan pendederan. Satu siklus pendederan membutuhkan waktu selama 10 bulan dimana ukuran spat mencapai 6-8 cm, laju pertumbuhan rata-rata $0,7 \mathrm{~cm}$ per bulan dengan survival rate (SR) sekitar 5-10\%. Kecilnya Survival rate (SR) pada saat pemeliharaan diduga karena adanya masa transisi dari pemeliharaan di lab hatchery yang kemudian dipindahkan ke laut. Pada satu periode telah ditemukan banyaknya kematian yang terjadi di saat spat berukuran kurang dari $3 \mathrm{~cm}$ (Direktorat Jenderal Perikanan Budidaya, 2013). Selama pemeliharaan atau pendederan, tiram mutiara memerlukan penanganan dan perawatan agar pertumbuhan dan perkembangan serta kelangsungan hidup terjaga. Seiring dengan meningkatnya ukuran tiram maka akan terjadi kompetisi terhadap ruang atau tempat pemeliharaan dan makanan/pakan. Bahkan ditemukan bahwa anakan tiram saling menempel sehingga perlunya dilakukan kegiatan penjarangan. Dengan penjarangan ini diharapkan pertumbuhannya menjadi normal dan tingkat kelangsungan hidup menjadi tinggi (Ghufran dan Kodi, 2011).

Menurut Gosling (2003), pertumbuhan tiram mutiara dipengaruhi oleh ketersediaan makanan. Hal yang sama di kemukakan Hamzah (2009) dalam Mariati (2011) bahwa pertumbuhan dan kelangsungan hidup tiram mutiara dipengaruhi oleh suhu dan ketersediaan makanan. Kisaran suhu normal untuk pertumbuhan tiram mutiara di laut adalah 26-300C (Setyonobudiandi, 1989); $\mathrm{pH}$ perairan 7,9-8,2 (Winanto, 2004); salinitas 32-35 ppt (Winanto, 2004); dan kecerahan berkisar antara 4,5-6,5 m (Mulyanto, 1987 ; Sutaman, 1993; dan Hamzah et al. 2005).

Salah satu faktor penting yang mempengaruhi pertumbuhan dan kelangsungan hidup tiram mutiara adalah kedalaman. Kedalaman berpengaruh terhadap salinitas, suhu, pH, dan kecerahan. Kedalaman perairan yang cocok untuk kegiatan budidaya mutiara adalah antara 15-20 m walaupun Pinctada maxima dapat hidup pada kedalaman
$60 \mathrm{~m}$ (Sutaman, 1993)). Pada kedalaman ini tiram mutiara dapat tumbuh dengan baik. Efek kedalaman terhadap pertumbuhan dan kelangsungan hidup Pinctada maxima telah banyak diteliti oleh para ahli. Hamzah (2007) di Teluk Kapantori menggunakan level kedalaman yang berbeda $(6 \mathrm{~m}, 10 \mathrm{~m}, 14 \mathrm{~m}, 18 \mathrm{~m}$, dan $22 \mathrm{~m}$ ) menyimpulkan bahwa kedalaman 22 m merupakan kedalaman terbaik untuk mencapai $100 \%$ kelangsungan hidup. Selanjutnya penelitian di Teluk Kombal lombok utara oleh Hamzah dan Sumandhiharga (2002) menyimpulkan bahwa pertumbuhan pertumbuhan dan kelangsungan hidup terbaik anakan tiram mutiara diperoleh pada kedalaman $4 \mathrm{~m}$. Hasil kedua penelitian tersebut menunjukkan bahwa pertumbuhan dan kelangsungan hidup Pinctada maxima sangat ditentukan oleh kedalaman dan lingkungan perairan tempat hidupnya.

Bertolak dari permasalahan tersebut diatas maka tujuan penelitian ini adalah untuk mengetahui pengaruh kedalaman yang berbeda dan kedalaman yang paling optimal/baik terhadap kelangsungan hidup (Survival Rate) benih tiram mutiara (Pinctada maxima) pada stadia spat.

\section{BAHAN DAN METODE.}

Penelitian dilakukan di perairan Teluk sekotong lombok barat pada bulan agustus oktober 2015 menggunakan metode eksperimen lokasi penelitian dapat dilihat pada gbr.1

Rancangan yang digunakan dalam penelitian ini adalah Rancangan Acak Lengkap (RAL) atau Completely Randomized Design (CRD). Sedangkan faktor yang akan diamati, yaitu 4 kedalaman yang berbeda antara lain :
$\mathrm{K} 1: 2 \mathrm{~m}$
$\mathrm{K} 3$ : $10 \mathrm{~m}$
$\mathrm{K} 2: 6 \mathrm{~m}$
$\mathrm{K} 4: \quad 14 \mathrm{~m}$

Masing-masing perlakuan tersebut diatas diulang sebanyak 3 kali, sehingga diperoleh 12 (dua belas) plot percobaan. Untuk lebih jelasnya dapat dilihat pada Tabel 1.

Parameter pengamatan yang akan diamati dalam penelitian ini terdiri dari dua, yaitu parameter Parameter utama dan penunjang.Parameter utama yang diamati adalah kelangsungan hidup (Survival Rate) 


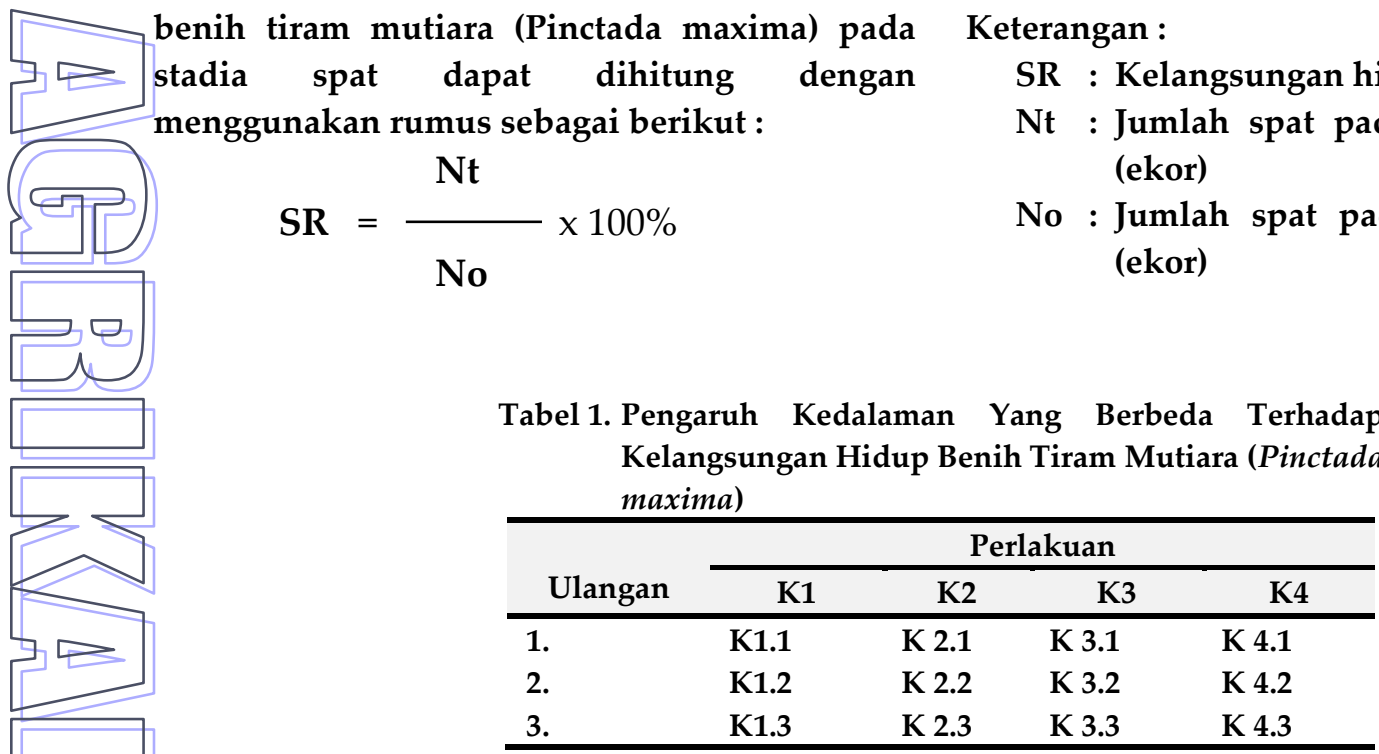

Parameter penunjang yang dimaksud adalah kualitas air media yang meliputi : Suhu (oC), Salinitas (ppt), pH (derajat keasaman), Kecepatan Arus,

Untuk mengetahui kelangsungan hidup (Survival Rate) benih tiram mutiara (Pinctada maxima) pada stadia spat selama penelitian dari

Tabel 2. Analisis Sidik Ragam (ANASRA)

\begin{tabular}{lclllll}
\hline \multirow{2}{*}{ SK } & DB & \multirow{2}{*}{ JK } & KT & \multirow{2}{*}{ F.Hitung } & \multicolumn{2}{c}{ F. Tabel } \\
\cline { 6 - 7 } & & & & Ko & $1 \%$ \\
Perlakuan & $\mathrm{p}-1$ & JKP & JKP/p-1 & KTP/KTS & & \\
\hline Total & $\mathrm{p}(\mathrm{n}-1)$ & JKS & JKS/p(n-1) & & & \\
\hline
\end{tabular}

Bila diantara perlakuan terdapat perbedaan yang nyata atau sangat nyata maka dilakukan uji lanjutan dengan mengunakan uji Beda Nyata Terkecil (BNT), dengan rumus :

$$
B N T=t . t a b \alpha \%(d b \text { sis } a) \sqrt{\frac{2 K T S}{n}}
$$

Pelaksanaan penelitian dimulaidengan mempersiapkan alat dan bahan, tiram mutiara yang digunakan dalam penelitian ini adalah Pinctada maxima hasil hatchery stadia spat dengan kondisi sehat, warnah cangkang cerah, tidak cacat serta pada cangkannya banyak tumbuh tunas/hasyaki baru. Pemeliharaan spat tiram mutiara dilakukan menggunakan pocket net di long line (tali rentang) pada kedalaman sesuai perlakuan. Selama melakukan penelitian, kantung pembungkus pocket net masing - masing perlakuan maka dilakukan Analisa Sidik Ragam (ANASRA) pada taraf $1 \%$ dan $5 \%$. Bila diantara perlakuan terdapat perbedaan yang nyata atau sangat nyata maka dilakukan uji lanjut dengan menggunakan BNT (Uji Beda Nyata Terkecil). Untuk lebih jelasnya dapat dilihat pada Tabel 2.

(warring) diganti setiap dua minggu sekali untuk membersihkan kotoran dan organisme penempel pada permukaan warring yang bisa menghalangi masuknya plankton yang dibutuhkan oleh spat tiram mutiara.

\section{HASIL DAN PEMBAHASAN}

Hasil penelitian tentang Perbedaan kedalaman terhadap tingkat kelangsungan hidup (Survival Rate) benih tiram mutiara (Pinctada maxima) pada stadia spat di Pengembangan di perairan Sekotong Kabupaten Lombok Barat, diperoleh hasil sebagai berikut :

1.1. Kelangsungan Hidup Benih Tiram Mutiara (Pinctada maxima)

Kelangsungan hidup adalah peluang hidup suatu individu dalam waktu tertentu, sedangkan mortalitas adalah kematian yang terjadi pada suatu populasi organisme yang menyebabkan berkurangnya jumlah individu 
di populasi tersebut (Hamzah, 2008). Tingkat kelangsungan hidup akan menentukan produksi yang diperoleh dan erat kaitannya dengan ukuran tiram mutiara yang dipelihara.

Pengamatan benih tiram mutiara (Pinctada maxima) pada stadia spat dilakukan sejak mulainya dilepaskan ke dalam perairan dengan sarana budidaya berupa long line selama penelitian sesuai dengan plot - plot percobaan yang telah di siapkan. Perlakuan kedalaman yang berbeda seperti pada K1 (kedalaman $2 \mathrm{~m}$ ), K2 (kedalaman $6 \mathrm{~m}$ ), K3 (kedalaman $10 \mathrm{~m}$ ) dan K4 (kedalaman $14 \mathrm{~m}$ ), sehingga diperoleh prosentase kelulusan hidup dari benih tiram mutiara (Pinctada maxima) pada stadia spat. Untuk lebih jelasnya dapat dilihat pada Tabel 3.

Tabel 3. Data Penghitungan Kelangsungan Hidup (Survival Rate) Benih Tiram Mutiara (Pinctada maxima) Pada Stadia Spat di Akhir Penelitian.

\begin{tabular}{|c|c|c|c|c|c|c|c|c|c|c|c|c|}
\hline \multirow{3}{*}{ Ulangan } & \multicolumn{12}{|c|}{ Perlakuan } \\
\hline & \multicolumn{3}{|c|}{ K1 } & \multicolumn{3}{|c|}{$\mathrm{K} 2$} & \multicolumn{3}{|c|}{ K3 } & \multicolumn{3}{|c|}{$\mathrm{K} 4$} \\
\hline & $\begin{array}{c}\text { No } \\
\text { (ekr) }\end{array}$ & $\begin{array}{c}\mathrm{Nt} \\
(\mathrm{ekr})\end{array}$ & $\begin{array}{l}\text { SR } \\
(\%)\end{array}$ & $\begin{array}{c}\text { No } \\
\text { (ekr) }\end{array}$ & $\begin{array}{c}\mathrm{Nt} \\
(\mathrm{ekr})\end{array}$ & $\begin{array}{l}\text { SR } \\
(\%)\end{array}$ & $\begin{array}{c}\text { No } \\
\text { (ekr) }\end{array}$ & $\begin{array}{c}\mathrm{Nt} \\
(\mathrm{ekr})\end{array}$ & $\begin{array}{l}\text { SR } \\
(\%)\end{array}$ & $\begin{array}{c}\text { No } \\
\text { (ekr) }\end{array}$ & $\begin{array}{c}\mathrm{Nt} \\
\text { (ekr) }\end{array}$ & $\begin{array}{l}\text { SR } \\
(\%)\end{array}$ \\
\hline 1 & 60 & 53 & 88 & 60 & 58 & 97 & 60 & 54 & 90 & 60 & 50 & 83 \\
\hline 2 & 60 & 55 & 92 & 60 & 55 & 92 & 60 & 43 & 72 & 60 & 45 & 75 \\
\hline 3 & 60 & 57 & 95 & 60 & 59 & 98 & 60 & 49 & 82 & 60 & 48 & 80 \\
\hline Jumlah & 180 & 165 & 275 & 180 & 172 & 287 & 180 & 146 & 244 & 180 & 143 & 238 \\
\hline Rata-Rata & 60 & 55 & 92 & 60 & 57 & 96 & 60 & 49 & 81 & 60 & 48 & 79 \\
\hline
\end{tabular}

Sumber : Data Primer Diolah

Dari tabel diatas, dapat dilihat bahwa kelangsungan hidup benih tiram mutiara (Pinctada maxima) pada stadia spat yang tertinggi terjadi pada perlakuan $\mathrm{K} 2$ (kedalaman $6 \mathrm{~m})$ dengan rata - rata prosentase kelangsungan hidup (Survival Rate/SR) sebesar 96\% dan dikuti oleh perlakuan K1 (kedalaman $2 \mathrm{~m})$ dengan rata-rata prosentase kelangsungan hidup (Survival Rate/SR) sebesar 92\% sedangkan terendah diperoleh pada perlakuan
K4 (kedalaman $14 \mathrm{~m})$ dengan rata-rata prosentase kelangsungan hidup (Survival Rate/SR) sebesar 79\%.

Berdasarkan hasil Analisa Sidik Ragam (ANASRA) menunjukkan bahwa kelangsungan hidup benih tiram mutiara (Pinctada maxima) stadia spat pada masing-masing perlakuan Tidak Berbeda Nyata (non signifikan) dimana F hitung < F tabel $5 \%(3,80<4.07)$. Untuk lebih jelasnya dapat dilihat pada Tabel 4 .

Tabel 4. Analisa Sidik Ragam (ANASRA) Pengaruh Kedalaman Yang Berbeda Terhadap Kelangsungan Hidup (Survival Rate) Benih Tiram Mutiara (Pinctada maxima) Pada Stadia Spat di Akhir Penelitian

\begin{tabular}{|c|c|c|c|c|c|c|}
\hline \multirow{3}{*}{$\begin{array}{l}\text { Sumber } \\
\text { Keragam }\end{array}$} & \multirow{3}{*}{ DB } & \multirow{3}{*}{ JK } & \multirow{3}{*}{ KT } & \multicolumn{3}{|c|}{ Uji F } \\
\hline & & & & \multirow{2}{*}{ F. Hitung } & \multicolumn{2}{|c|}{ F. Tabel } \\
\hline & & & & & $5 \%$ & $1 \%$ \\
\hline Perlakuan & 3 & 574,92 & 191,64 & $3,80^{\mathrm{NS}}$ & 4,07 & 7,59 \\
\hline Sisa & 8 & 403 & 50,38 & & & \\
\hline Total & 11 & & & & & \\
\hline
\end{tabular}

Dari hasil Analisa Sidik Ragam (ANASRA) tersebut diatas maka tidak dilakukan uji lanjut BNT dikarenakan F hitung lebih kecil dibandingkan nilai uji $\mathrm{F}$ tabel pada taraf $5 \%$.

Berdasarkan analisa hasil penelitian untuk mengetahui pengaruh kedalaman yang berbeda terhadap kelangsungan hidup
(Survival Rate) benih tiram mutiara (Pinctada maxima) pada stadia spat di perairan Sekotong Kabupaten Lombok Barat menunjukkan bahwa perlakuan K2 (kedalaman $6 \mathrm{~m}$ ) memiliki prosentase kelangsungan hidup (SR)lebih tinggi dengan rata-rata prosentase sebesar $96 \%$ dan dikuti oleh perlakuan K1 (kedalaman $2 \mathrm{~m}$ ) sebesar $92 \%$ sedangkan terendah diperoleh 
pada perlakuan K4 (kedalaman $14 \mathrm{~m}$ )) sebesar $79 \%$. Hal ini senada dengan hasil penelitian Hamzah (2009) di perairan Teluk Kodek, berdasarkan kedalaman yang berbeda yaitu 2, 6, 8 dan $14 \mathrm{~m}$, menunjukkan bahwa kedalaman $2 \mathrm{~m}$, dan $6 \mathrm{~m}$ tingkat persentase kelangsungan hidup anakan kerang mutiara yaitu sebesar 100 $\%$, kemudian disusul pada kedalaman $14 \mathrm{~m}$ sebesar $80 \%$. Anakan tiram mutiara yang diteliti yaitu dari stadia lebar cangkang 23,11 sampai 24,19 $\mathrm{mm}$. Sedangkan hasil penelitian Hamzah dan Nababan (2008) di perairan Teluk Kapontori, bahwa kelangsungan hidup anakan tiram mutiara yang berukuran 32 sampai $34 \mathrm{~mm}$ dinilai berhasil jika diletakkan pada kedalaman $2 \mathrm{~m}$ dan $6 \mathrm{~m}$. Hal ini diduga dipengaruhi oleh faktor kecepatan arus permukaan yang lebih besar dibandingkan dengan kecepatan arus di bawahnya, sedangkan faktor lingkungan (suhu, salinitas dan $\mathrm{pH}$ ) selama pengamatan pada kedalaman 2 m tidak berbeda pada kedalaman lainnya. Faktor kecepatan arus permukaan mungkin dapat berpengaruh terhadap peningkatan ketersediaan makanan dan faktor fisiologi dan ekologi yang lebih sesuai terhadap perkembangan dan pertumbuhan anakan kerang mutiara (Hamzah, 2008).

Berdasarkan hasil Analisa Sidik Ragam (ANASRA) kelangsungan hidup benih tiram mutiara (Pinctada maxima) stadia spat pada masing-masing perlakuan Tidak Berbeda Nyata (non signifikan) dimana F hitung < F tabel $5 \%$ $(3,80<$ n 4.07).

\subsection{Parameter Kualitas Air}

Kualitas air dalam budidaya adalah salah satu faktor yang mempengaruhi kelangsungan hidup, perkembang biakan, pertumbuhan dan produksi dari biota yang dipelihara. Air sebagai media budidaya harus disesuaikan dengan keadaan di alam serta sesuai dengan kemampuan organisme dalam menyesuaikan diri. Parameter yang berpengaruh terhadap pertumbuhan spat tiram mutiara diantaranya adalah : suhu, salinitas, kecepatan arus dan $\mathrm{pH}$.

Hasil pengamatan kualitas air media pemeliharaan larva tiram mutiara (P. maxima) selama penelitian disajikan pada tabel 5 berikut ini :

Tabel 5. Data Hasil Pengukuran Paramter Kualitas Air Pengaruh Kedalaman Yang Berbeda Terhadap Kelangsungan Hidup (Survival Rate) Benih Tiram Mutiara (Pinctada maxima) Pada Stadia Spat.

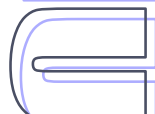

\begin{tabular}{|c|c|c|c|c|c|c|c|c|c|}
\hline \multirow[b]{2}{*}{ Hari ke.... } & \multicolumn{3}{|c|}{ Pengamatan Suhu $\left({ }^{\circ} \mathrm{C}\right)$} & \multicolumn{3}{|c|}{ Pengamatan pH } & \multicolumn{3}{|c|}{ Pengamatan Salinitas (ppt) } \\
\hline & Pagi & Siang & Sore & Pagi & Siang & Sore & Pagi & Siang & Sore \\
\hline 1 & 27,5 & 27,5 & 27,9 & 7 & 7 & 7 & 33 & 33 & 33 \\
\hline 3 & 27,6 & 27,6 & 27,7 & 7 & 7 & 8 & 33 & 33 & 33 \\
\hline 5 & 27,5 & 27,9 & 27,8 & 7 & 7 & 8 & 33 & 33 & 33 \\
\hline 7 & 27,7 & 28 & 28 & 7 & 8 & 7 & 34 & 34 & 34 \\
\hline 9 & 28,6 & 28,5 & 28,9 & 7 & 8 & 7 & 34 & 34 & 34 \\
\hline 11 & 27,9 & 28 & 28 & 7 & 8 & 8 & 34 & 34 & 34 \\
\hline 13 & 27,6 & 27,8 & 27,8 & 7 & 7 & 7 & 33 & 33 & 33 \\
\hline 15 & 27 & 26,9 & 27,8 & 8 & 7 & 7 & 33 & 33 & 33 \\
\hline 17 & 26,9 & 26,8 & 27,8 & 8 & 7 & 8 & 32 & 32 & 32 \\
\hline 19 & 27 & 27,4 & 27,9 & 8 & 8 & 8 & 32 & 32 & 32 \\
\hline 21 & 27,9 & 27,5 & 28,1 & 7 & 8 & 7 & 32 & 32 & 32 \\
\hline 23 & 27,5 & 27,5 & 27,8 & 7 & 7 & 7 & 33 & 33 & 33 \\
\hline 25 & 27,5 & 27,8 & 28,4 & 8 & 7 & 7 & 33 & 33 & 33 \\
\hline 27 & 27,5 & 27,8 & 27,9 & 8 & 8 & 7 & 33 & 33 & 33 \\
\hline 29 & 27,7 & 28 & 28 & 7 & 7 & 8 & 33 & 33 & 33 \\
\hline 31 & 28,5 & 28,8 & 28 & 7 & 7 & 7 & 34 & 34 & 34 \\
\hline Kisaran & \multicolumn{3}{|c|}{$26,8-28,9$} & \multicolumn{3}{|c|}{$7-8$} & \multicolumn{3}{|c|}{$32-34$} \\
\hline Rata-rata & \multicolumn{3}{|c|}{28} & \multicolumn{3}{|c|}{7} & \multicolumn{3}{|c|}{33} \\
\hline
\end{tabular}

1. Suhu

Suhu air mempunyai pengaruh yang sangat penting terhadap proses metabolisme atau aktifitas biologis tiram mutiara, selain itu suhu juga berpengaruh terhadap kadar oksigen terlarut dalam air, pertumbuhan dan nafsu 
makan organisme perairan (Gulfran et al, 2007). Perubahan suhu mempengaruhi proses fisika, kimia dan biologi badan perairan. Hal ini dapat dilihat dengan adanya peningkatan kecepatan metabolisme pada larva apabila suhu suatu perairan meningkat dan sebaliknya penurunan suhu dapat menyebabkan metabolisme larva dan spat berkurang (larva dan spat tidak mau makan).

Suhu air di lokasi penelitian selama pemeliharaan masih berada pada kisaran yang baik untuk pemeliharaan spat yaitu pada kisaran 26,8 - 28,9 ${ }^{\circ} \mathrm{C}$. Untuk lebih jelasnya dapat dilihat pada Gambar 1.

Pada grafik terlihat terjadi penurunan suhu dari $29^{\circ} \mathrm{C}$ menjadi $26,8^{\circ} \mathrm{C}$ pada hari ke 5-8 dan 9 , kemudian bertahap kondisi suhu media air mulai naik kembali sampai pada hari ke 16 . Hal ini disebabkan karena terjadinya hujan yang berlangsung walaupun tidak secara terus menerus, namun masih dalam kondisi normal dan sesuai untuk kehidupan spat tiram mutiara. Menurut Matsui (1960) dalam Mulyanto (1987), syarat hidup tiram mutiara adalah pada kisaran suhu $26^{\circ} \mathrm{C}-2^{\circ} \mathrm{C}$, hal ini tidak jauh berbeda dengan yang dinyatakan Winanto (2001), bahwa larva dan spat tiram mutiara mempunyai pertumbuhan yang baik pada kisaran $26^{\circ} \mathrm{C}$ $2^{\circ} \mathrm{C}$. Menurut Sutaman (1993), tiram mutiara mampu bertahan pada kisaran suhu $28^{\circ} \mathrm{C}-30^{\circ} \mathrm{C}$.

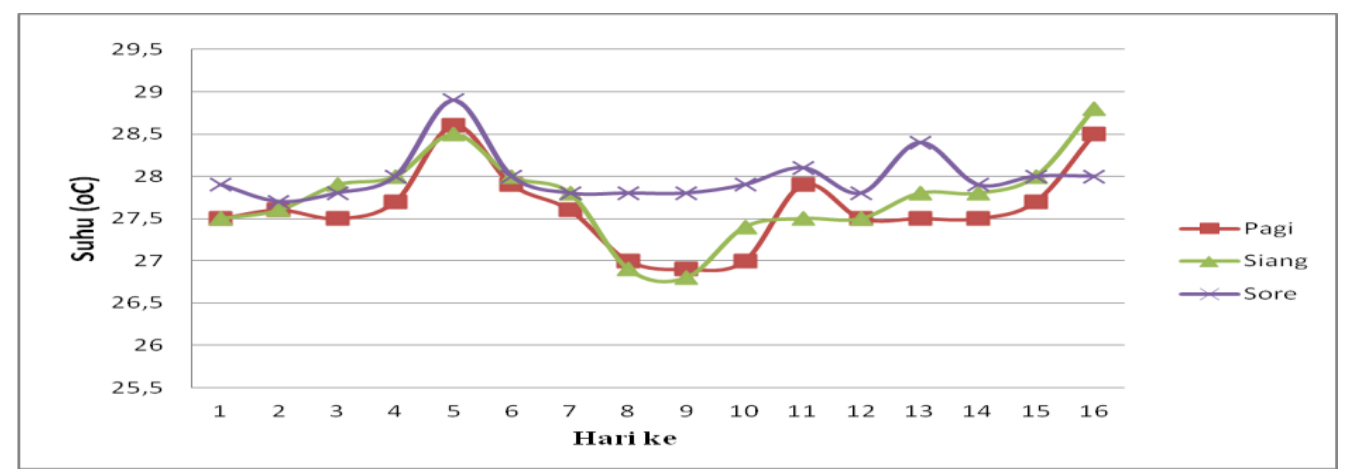

Gambar 1. Grafik Pengukuran Suhu Pada Penelitian Kelangsungan Hidup Benih Tiram Mutiara (Pinctada maxima)

\section{Salinitas}

Salinitas perairan terbuka biasanya berkisar antara 32 sampai 37,5 ppt. Perbedaanperbedaan mencerminkan pengaruh lokal dari penguapan, hujan, peleburan es, atau masuknya air (Mariari, S, 2011)). Hasil pengukuran salinitas terjadi peningkatan pada hari ke 4 - 6, hal ini disebabkan terjadinya peningkatan suhu. Peningkatan salinitas ini berbanding lurus dengan kenaikan suhu. Pada saat penurunan suhu, di lokasi penelitian sempat mengalami hujan besar sehingga salinitas air laut bercampur dengan air hujan (tawar) dan mengakibatkan penurunan terhadap salinitas. Hasil pengukuran salinitas di lokasi penelitian berkisar antara $32-34$ ppt dengan rata-rata 33 ppt. Grafik pengukuran salinitas pada pemeliharaan benih tiram mutiara selama penelitian dapat dilihat pada Gambar 2.

Menurut Tun dan Winanto (1988), baik Pinctada maxima maupun Pinctada margaritifera dapat bertahan hidup pada salinitas lebih tinggi antara 34-35 ppt. Hal yang sama juga dinyatakan Sutaman (1993), bahwa pada salinitas 20-50 ppt masih memungkinkan bagi tiram mutiara untuk hidup.Sedangkan berdasarkan Hamzah (2006) pada salinitas 14 ppt dan 50 ppt dapat mengakibatkan kematian kerang mutiara hingga mencapai $100 \%$. Menurut Nontji (1984) dalam Supriatna (2008) suhu perairan akan semakin rendah apabila perairan semakin dalam dan sebaliknya salinitas akan semakin meningkat.

\section{3. $\mathrm{pH}$}

Besarnya derajat keasaman $(\mathrm{pH})$ suatu perairan dapat berpengaruh terhadap tiram mutiara, penurunan $\mathrm{pH}$ air laut dari 8,1 menjadi 6,1 menurunkan getaran cillia $37 \%$ (Matsui, 1960 dalam Mulyanto, 1987). Pengukuran terhadap nilai $\mathrm{pH}$ pada lokasi pemeliharaan plot percobaan menunjukkan pada kisaran yang stabil yakni 7 - 8. Fluktuasi nilai $\mathrm{pH}$ air media 


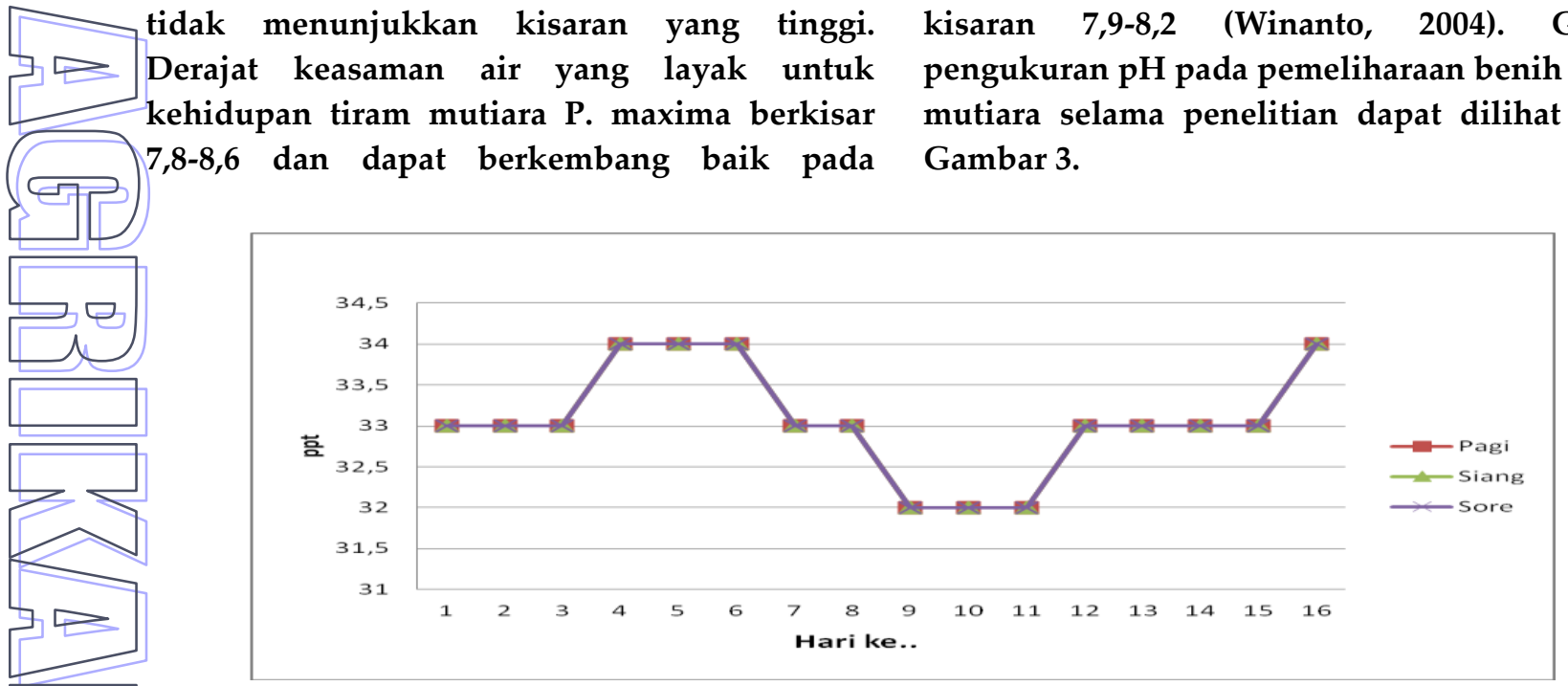

Gambar 2. Grafik Pengukuran Salinitas Pada Penelitian Kelangsungan Hidup Benih Tiram Mutiara (Pinctada maxima)

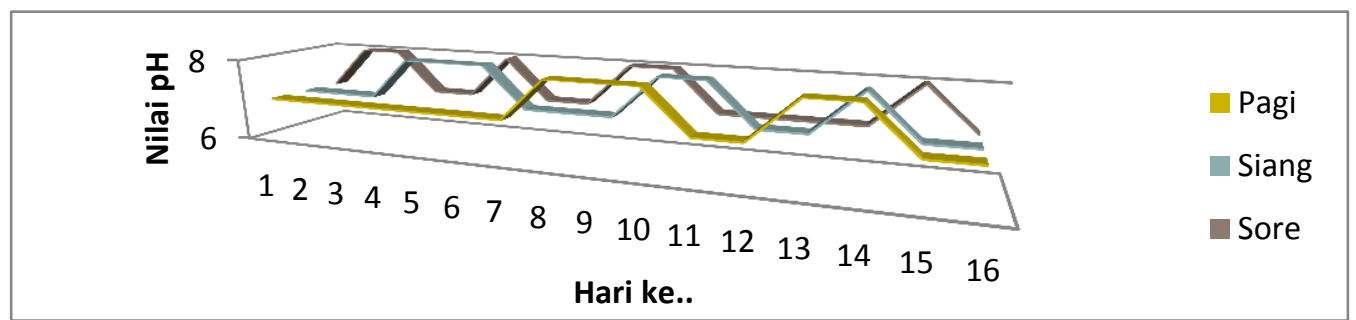

Gambar 3. Grafik Pengukuran pH Pada Penelitian Kelangsungan Hidup Benih Tiram Mutiara (Pinctada maxima)

4. Kecepatan Arus

Banyak sedikitnya kelimpahan plankton sebagai makanan alami tiram sangat tergantung pada kuat tidaknya arus yang mengalir dilokasi tersebut. Tiram mutiara memiliki sifat filter feeder. Oleh karena itu tiram mutiara akan mudah kelaparan pada kondisi arus yang terlalu kuat yang terjadi selama berjam-jam dalam sehari. Hal ini sesuai dengan Winanto (2004) menyatakan bahwa selama stadia larva, kerang mutiara bersifat planktonik dan pergerakanya dengan cilia pada velum yang lemah, sehingga banyak dipengaruhi oleh arah arus. Lokasi yang cocok untuk budidaya tiram mutiara yaitu terlindung dari arus yang kuat. Disamping itu pasang surut yang terjadi mampu menggantikan massa air secara total dan teratur, sehingga ketersediaan oksigen terlarut maupun plankton segar dapat terjamin. Grafik pengukuran kecepatan arus pada pemeliharaan spat tiram mutiara selama penelitian dapat dilihat pada Gambar 4 .

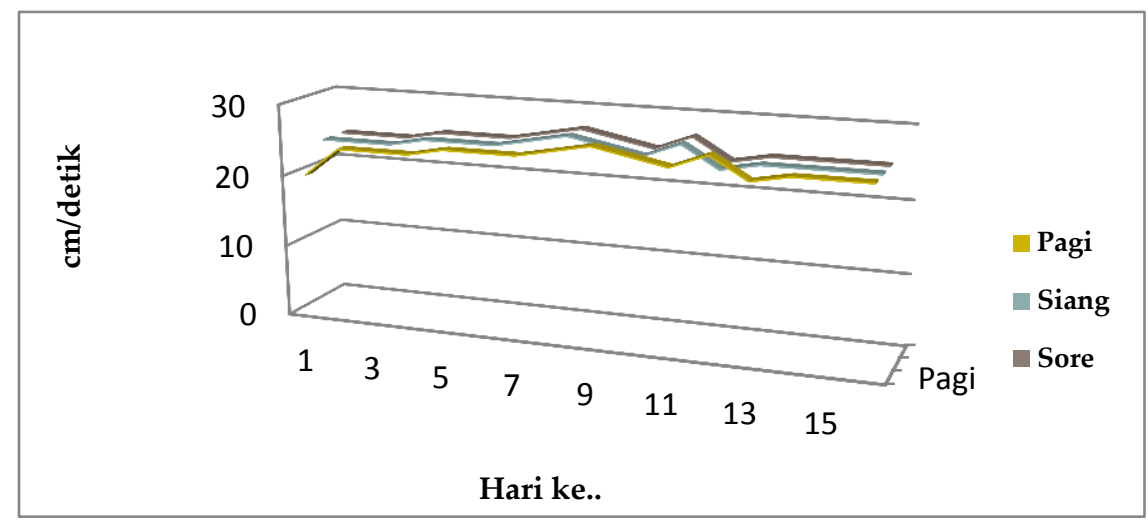

Gambar 4. Grafik Pengukuran Kecepatan Arus Pada Penelitian Kelangsungan Hidup Benih Tiram Mutiara (Pinctada maxima) 
Berdasarkan grafik diatas hasil pengamatan kecepatan arus di lokasi penelitian berkisar antara $20-27 \mathrm{~cm} /$ detik dengan rata rata yaitu $25 \mathrm{~cm} /$ detik. Hasil penelitian Sudradjat (2008) menyatakan bahwa secara umum kerang mutiara menyukai daerah dengan kecepatan arus berkisar antara 20-40 $\mathrm{cm} /$ detik.

\section{PENUTUP}

Dari hasil penelitian dan analisa terhadap data dapat disimpulkan sebagai berikut :

1. Kedalaman pemeliharaan spat yang berbeda memberikan pengaruh yang berbeda pula terhadap kelangsungan hidup/Survival Rate (SR) benih tiram mutiara (Pinctada maxima) pada stadia spat, dimana ditemukan pertumbuhan dan kelangsungan hidup hampir berbeda pada tiap kedalaman walaupun dengan jumlah tidak terlalu tinggi.
2. Kedalaman pemeliharaan paling optimal/baik untuk kelangsungan hidup (SR) spat tiram mutiara (Pinctada maxima) stadia spat tertinggi pada perlakuan K2 (kedalaman $6 \mathrm{~m}$ ) dengan prosentase sebesar $96 \%$ dan dikuti oleh perlakuan K1 (kedalaman 2 meter) sebesar 92\% sedangkan terendah diperoleh pada perlakuan K4 (kedalaman 14 meter) sebesar $79 \%$.

3. Berdasarkan hasil Analisa Sidik Ragam (ANASRA) menunjukkan bahwa kelangsungan hidup benih tiram mutiara (Pinctada maxima) stadia spat pada masingmasing perlakuan Tidak Berbeda Nyata (non signifikan) dimana $\mathrm{F}$ hitung $<\mathrm{F}$ tabel 5 $\%(3,80<4.07)$.

4. Pengamatan kualitas air selama penelitian meliputi : suhu berkisar antara 26,8 -28,9 oC, derajat keasaman (pH) air 7-8, salinitas 32-34 ppt dan kecepatan arus antara $20-27 \mathrm{~cm} /$ detik.

\section{DAFTAR PUSTAKA}

Gosling, Elizabeth. 2003. Bivalve Moluscs: Biology and culture. Fishing news Books, UK.443 P.

Ghulfran, M., et al, 2007. Pengelolaan Kualitas Air dalam Budidaya Perairan . Rineka Cipta Jakarta.

Hamzah, M.S. dan K. Sumandhiharga, 2002. Studi laju pertumbuhan dan kelangsungan hidup anakan kerang mutiara (Pinctada maxima) pada kedalaman yang berbeda di perairan Teluk Kombal - Lombok barat.

Hamzah, et al, 2005. Kelangsungan hidup anakan kerang mutiara (Pinctada maxima) dan fenomena arus dingin di perairan Teluk Kombal, Lombok barat; Prosiding pertemuan ilmiah tahunan ISOI, Jakarta 10-11 Desember 2003.

Hamzah, M.,S., 2006. Kelangsungan hidup anakan kerang mutiara (Pinctada maxima) dan fenomena arus dingin di perairan Teluk Kapantori, Pulau Buton-Sulawesi tenggara. Dalam; Prosiding semnas kelautan III,Univ.Hang Tuah,surabaya 24 April 2007: 80-86.

Hamzah, M.,S., 2007. Pengaruh warna jaring sebagai spat kolektor terhadap daya penempelan larva kerang mabe (Pteria penguin) di teluk kapantori, Pulau Buton-Sulawesi Tenggara. Makalah seminar nasional kelautan III 24 april 2007 di Universitas Hangtuah-Surabaya ; 12 hal.

Hamzah, M.,S., 2008. Kelangsungan hidup anakan kerang mutiara (Pinctada maxima) dengan pemberian jenis pakan yang berbeda. Prosiding seminar nasional kelautan IV, Uni. Hang Tuah, Surabaya: II-178-III83.

Hamzah, M.,S., 2009. Daya dukung lokasi Teluk Kapantori pengaruhnya terhadap kelangsungan hidup dan kualitas mutiara kerang mabe (Pteria penguin) menggunakan warna nukleus yang berbeda. Dalam prisiding Seminar Nasional, Kebijakan dan penelitian di bidang pertanian untuk pencapaian kebutuhan pangan dan agroindustri; Dies Natalis ke-42 Fakultas pertanian Unram : 120-130.

Hamzah, M.,S., dan Nababan., B.2008. Studi pertumbuhan dan kelangsungan hidup anakan kerang mutiara (Pinctada maxima) pada kedalaman berbeda di Teluk Kapantori, Pulau Buton. E-jurnal dan teknologi kelautan tropis. Vol. 1. (2) : 22 - 32. 
Mariati, S., 2011. Pengaruh kedalaman terhadap pertumbuhan dan prosentase kelangsungan hidup benih kerang mutiara (Pinctada maxima) pada stadia spat kolektor . Fakultas pertanian Universitas Mataram. Mataram.

Mulyanto, 1987. Buku prosiding seminar nasional budidaya kerang mutiara di indonesia, diselenggarakan di auditorium, Departemen Pertanian Jakarta.

Mulyanto, S. 1987. Teknik Budidaya Laut Tiram Mutiara di Indonesia. Diktat Ahli Usaha Perikanan. Jakarta Hal-70.

Sutaman, 1993. Teknik Budidaya dan Proses Pembuatan Mutiara. Kanisius. Yogyakarta. Hal 93.

Supriatna, 2008. Fluktuasi Penempelan Benih Tiram (Crassostrea spp) kerang dan Teritip di Perairan Pulau Numbing. Riau. Coastal Aquaculture Research Jurnal. Balai Penelitian

Budidaya Panttai. Maros. Hal $73-80$.
Tun, M. T dan T.Winanto, 1988. Petunjuk Budidaya Mutioara di Indonesia. Sea Farming
Development Project. Jakarta. Hal 65.

Y Winanto, T. 2004. Memproduksi Tiram Mutiara. Penebar swadaya. Jakarta. Hal 95.

Winanto, T., Dedi S., Ridwan, A., Harpasis S. Sanusi. 2009. Pengaruh Suhu dan Salinitas Terhadap Respon Fisiologi Larva Tiram Mutiara (Pinctada maxima). Jurnal Biologi Indonesia. Vol. 6, no.1. 19 hal

Winanto dan S. Basi Dhoe. 2001. Rekayasa Teknologi Pemeliharaan Tiram Mutiara (Pinctada maxima). Pertemuan Koordinasi dan Pemantapan Rekayasa Teknologi Pembenihan Lintas UPT. Direktorat Jendral Perikanan. Bogor

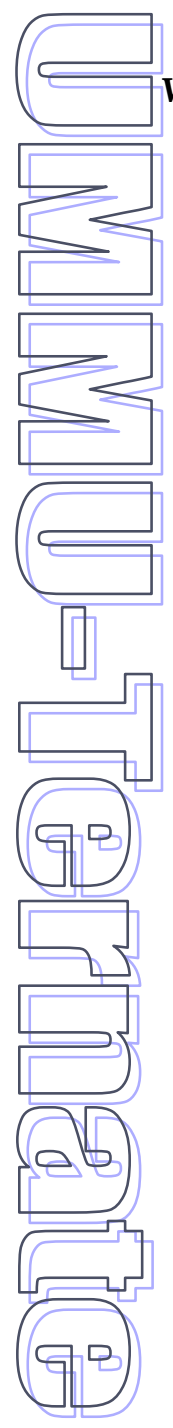

Winanto, Pontjoprawiro dan M. Murdjani. 1988. Budidaya Tiram Mutiara. Direktorat Jendral Perikanan. Balai Budidaya laut Lampung. Lampung. Hal $45 .$. 